\title{
Particle size distributions of organic aerosol constituents during the 2002 Yosemite Aerosol Characterization Study
}

\author{
Pierre Herckes ${ }^{+}$, Guenter Engling, Sonia M. Kreidenweis \\ Jeffrey L. Collett, Jr.*
}

Supporting information 


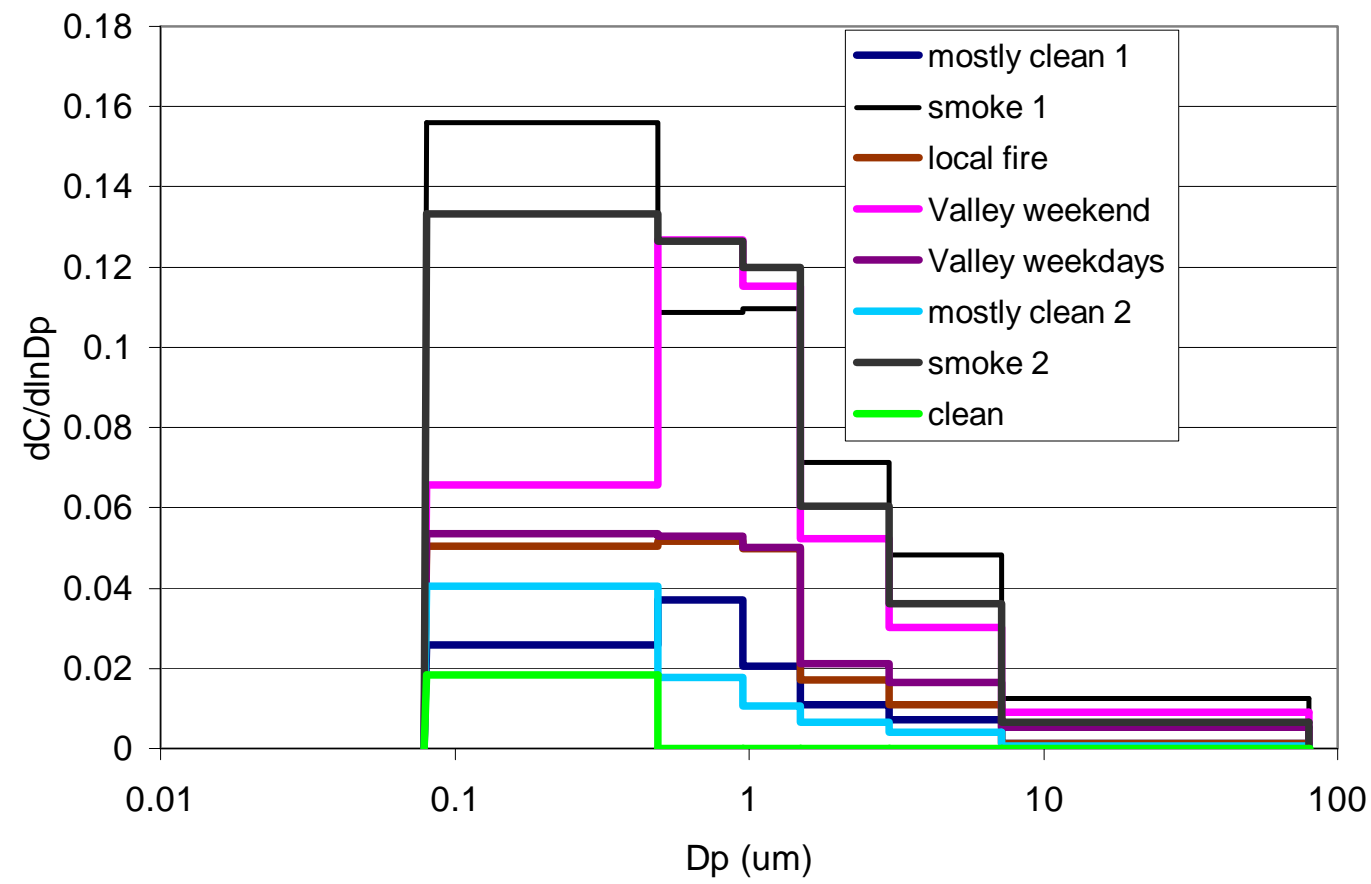

Figure A. Particle size distributions of acetovanillone. 


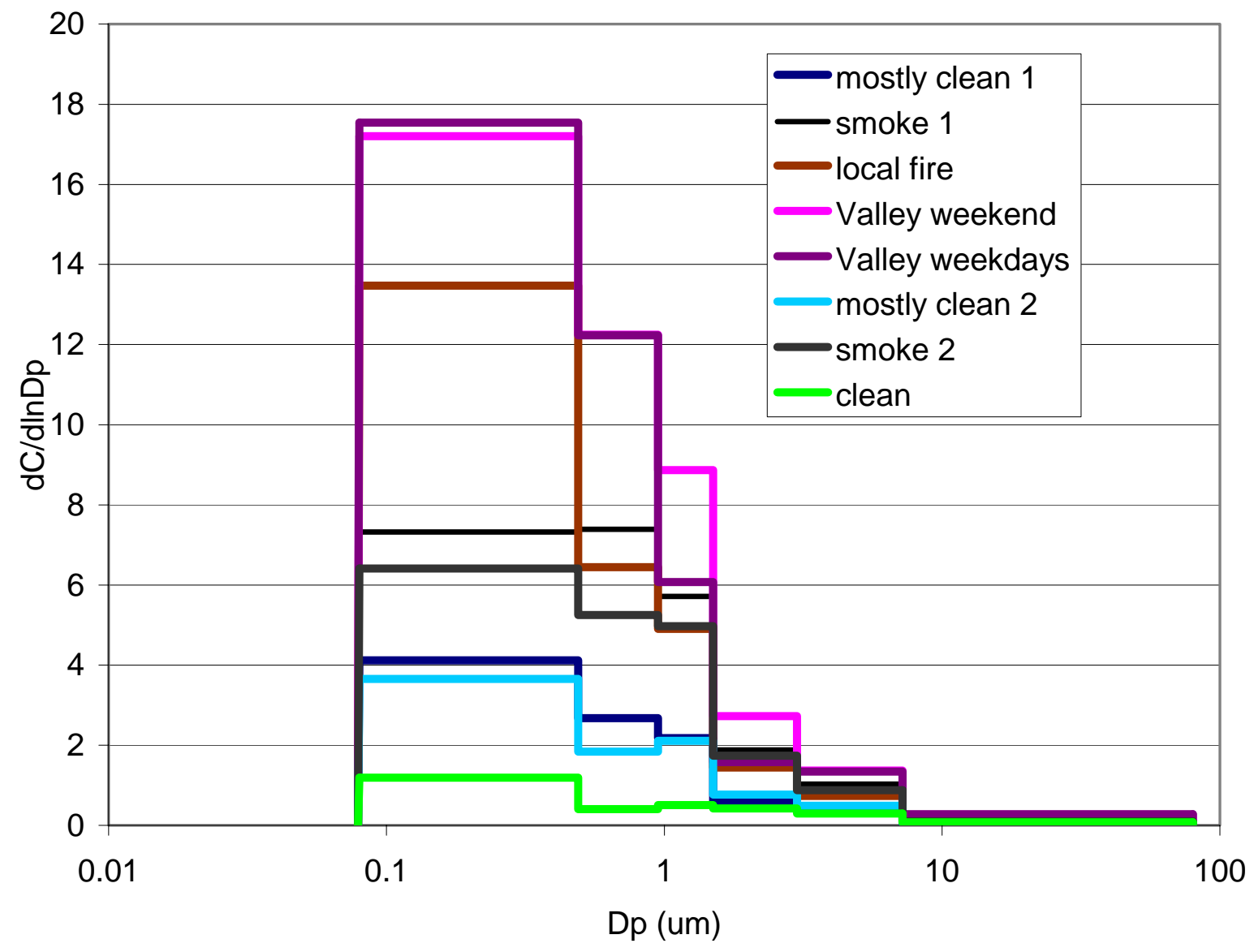

Figure B. Particle size distributions of dehydroabietic acid 


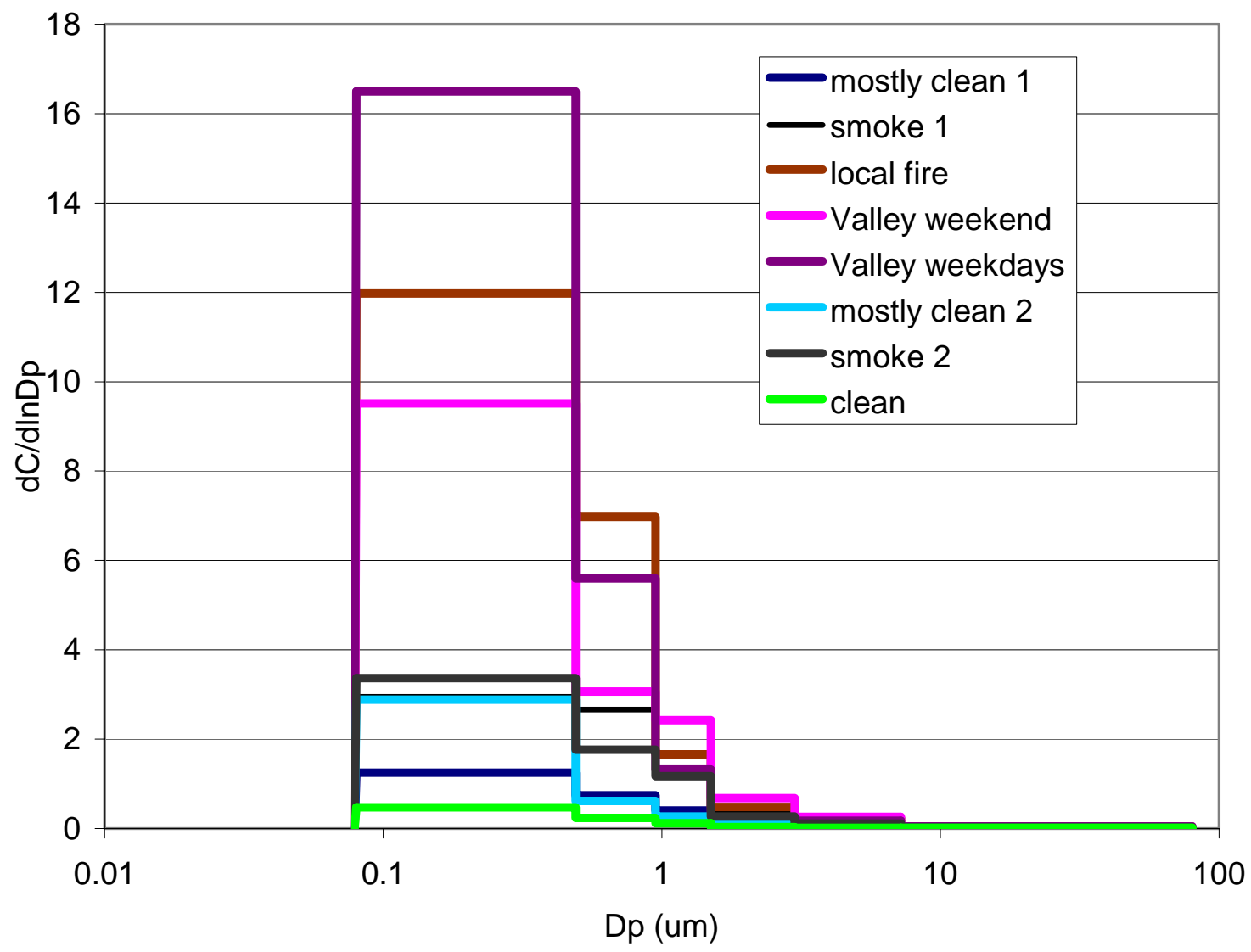

Figure C. Particle size distributions of 7-oxo-dehydroabietic acid observed during YACS. 


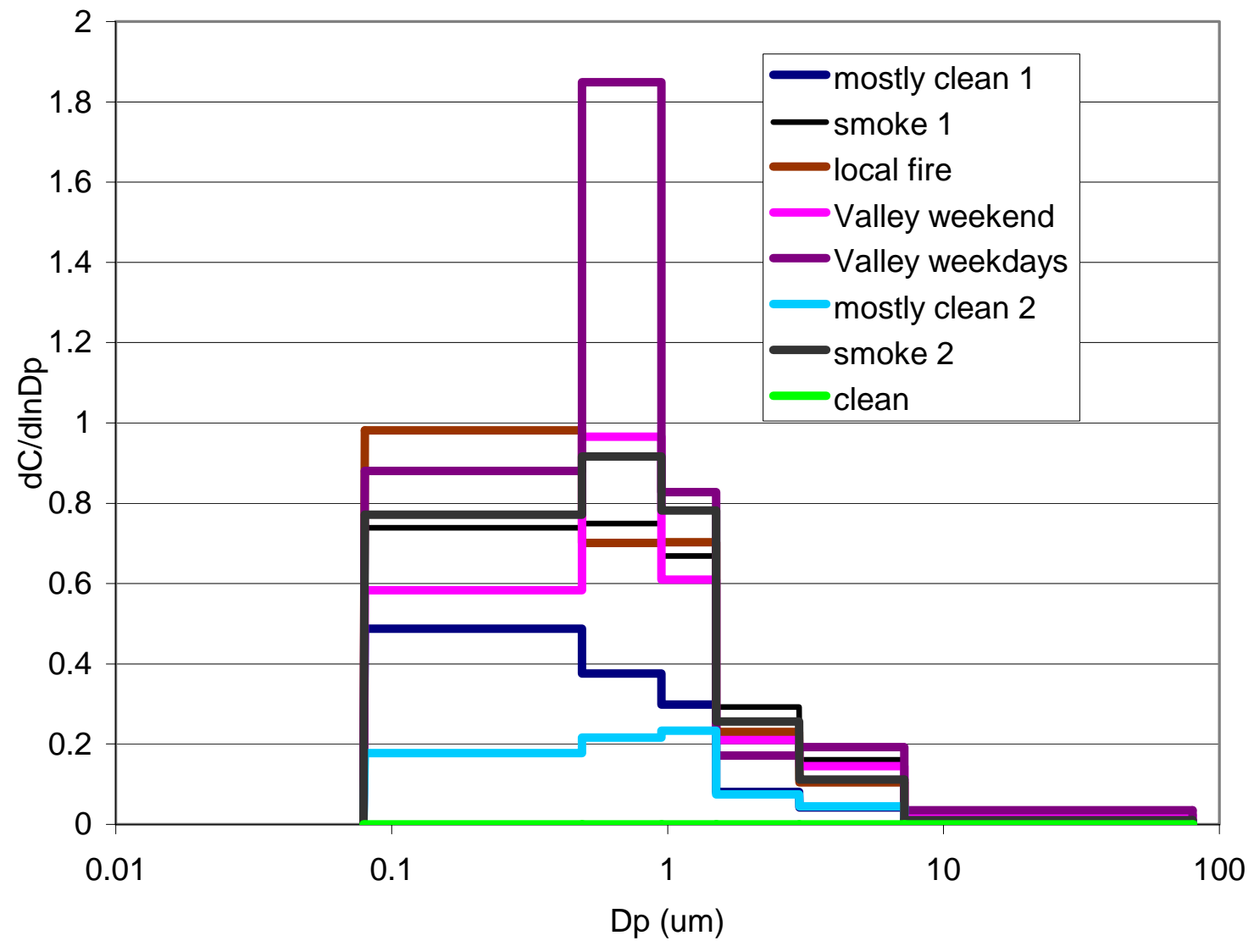

Figure D. Particle size distributions of isopimaric acid observed during YACS. 


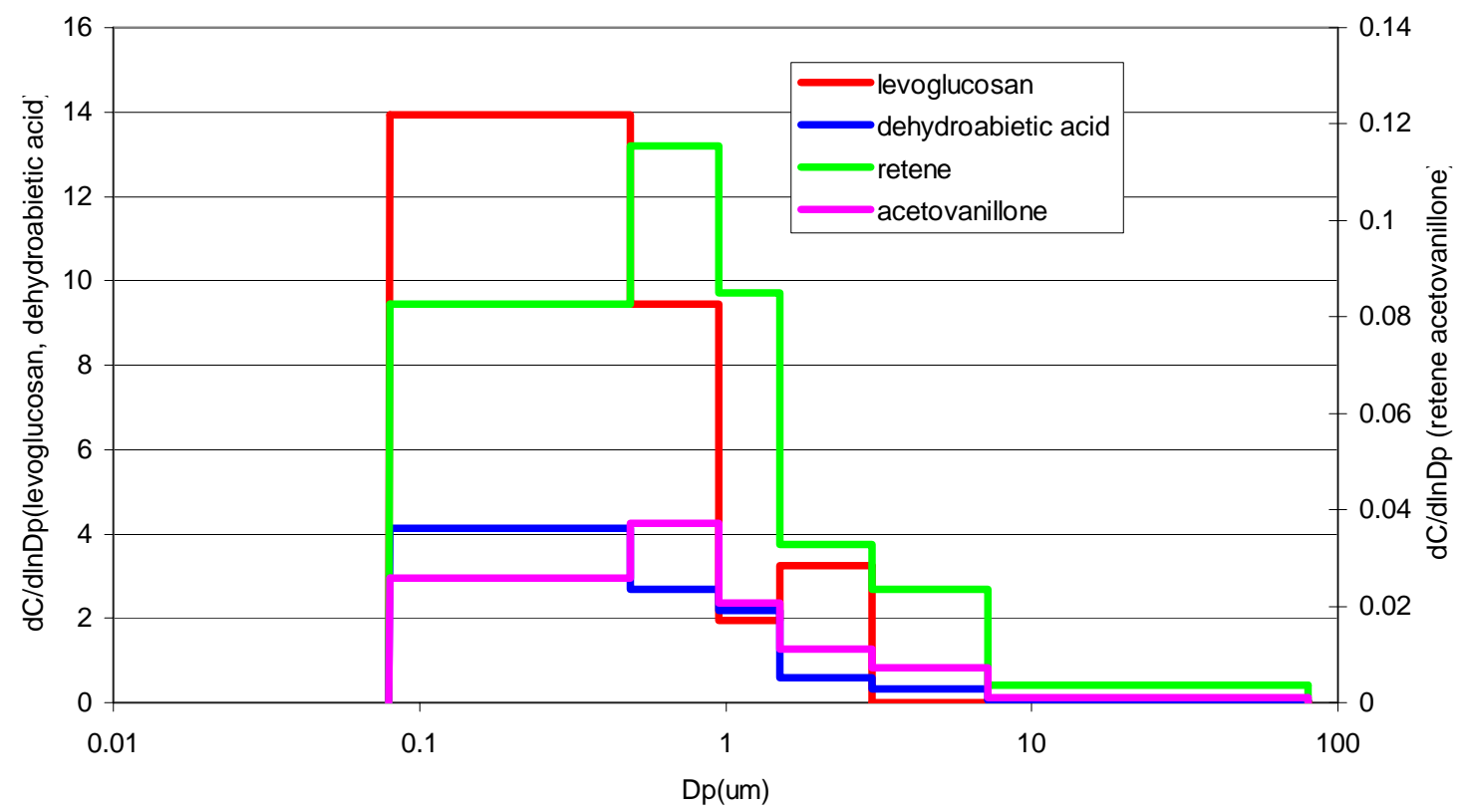

Figure E Particle size distributions of selected wood smoke markers for sample YS072501 “mostly clean 1”. 




Figure F. Particle size distributions of resin acids for sample "smoke 2". 


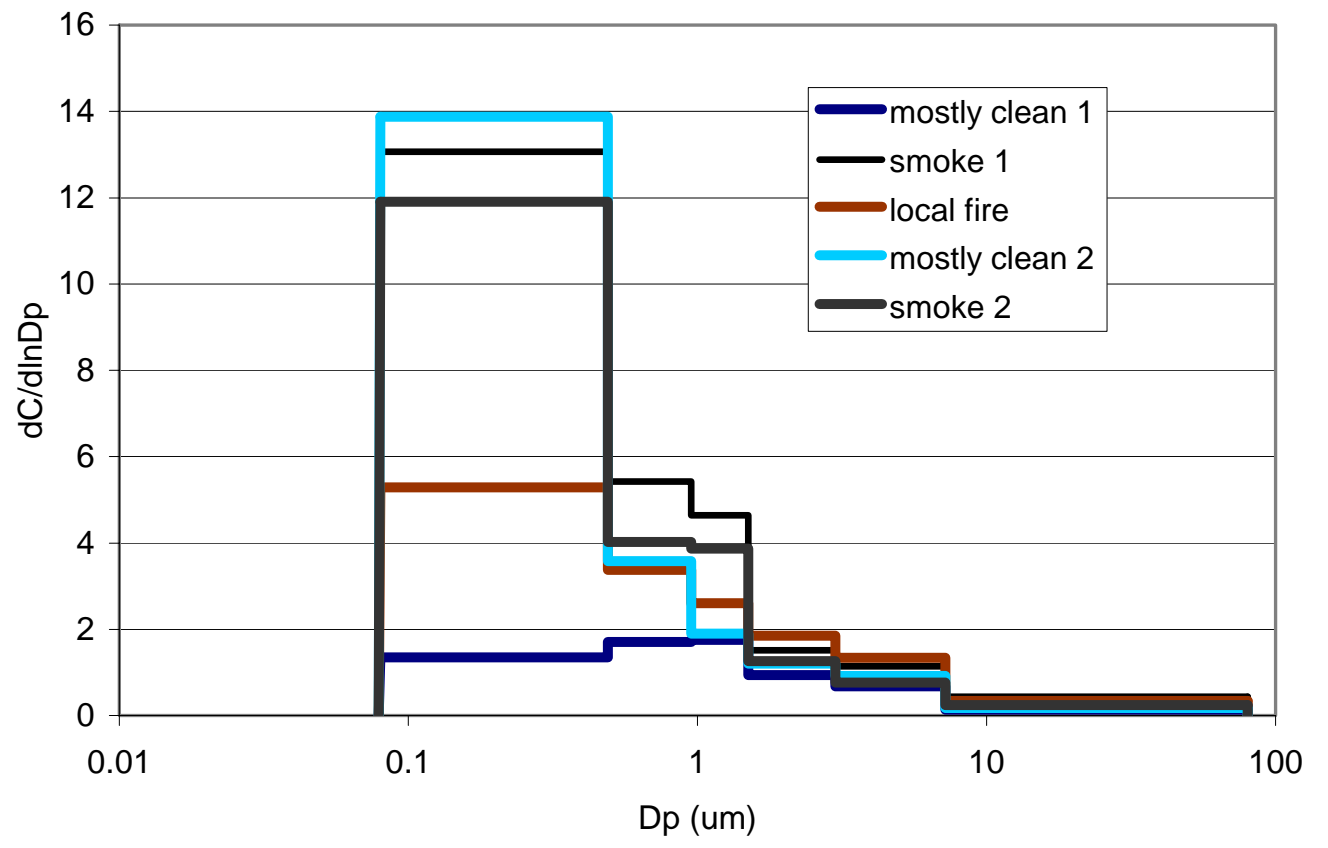

Figure G. Particle size distribution of pinonic acid. 


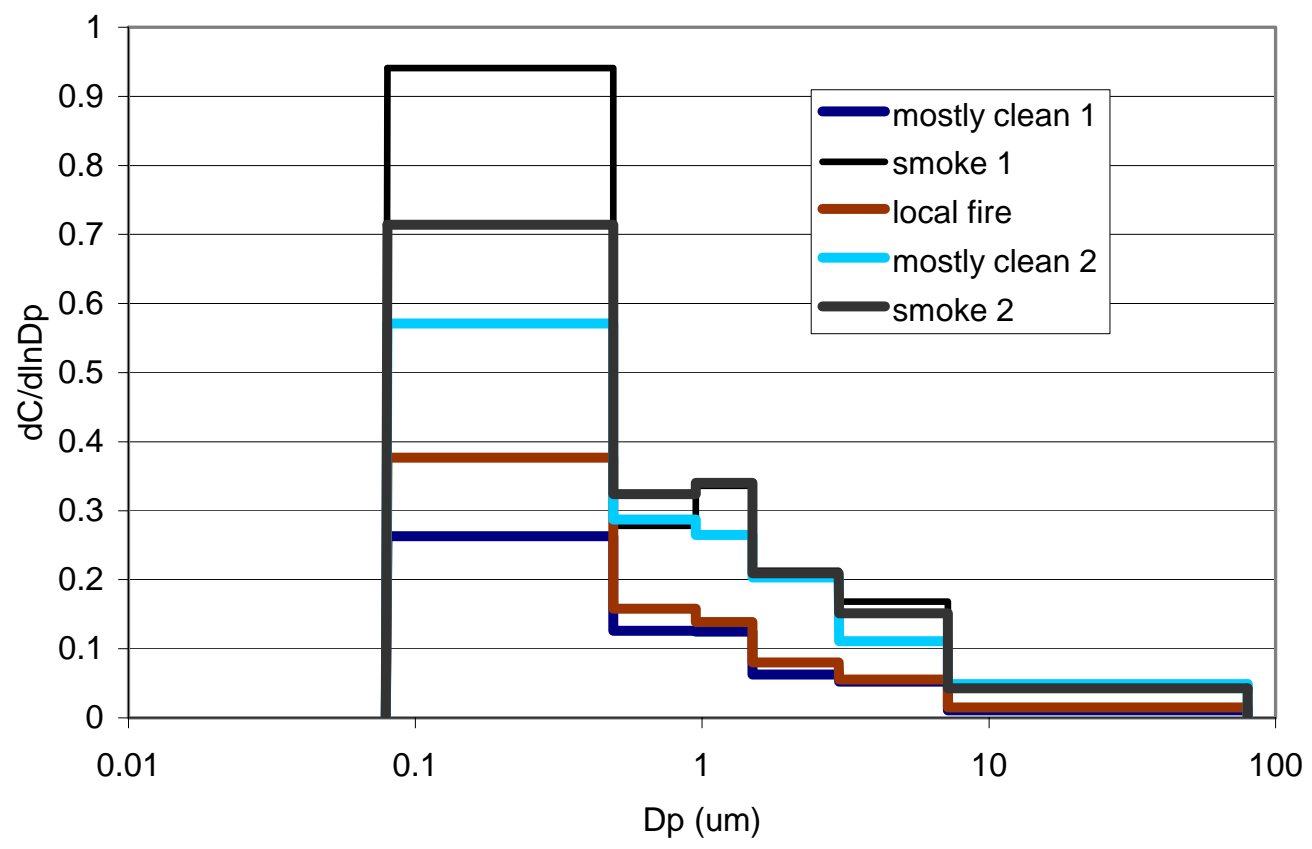

Figure H. Particle size distribution of nopione. 


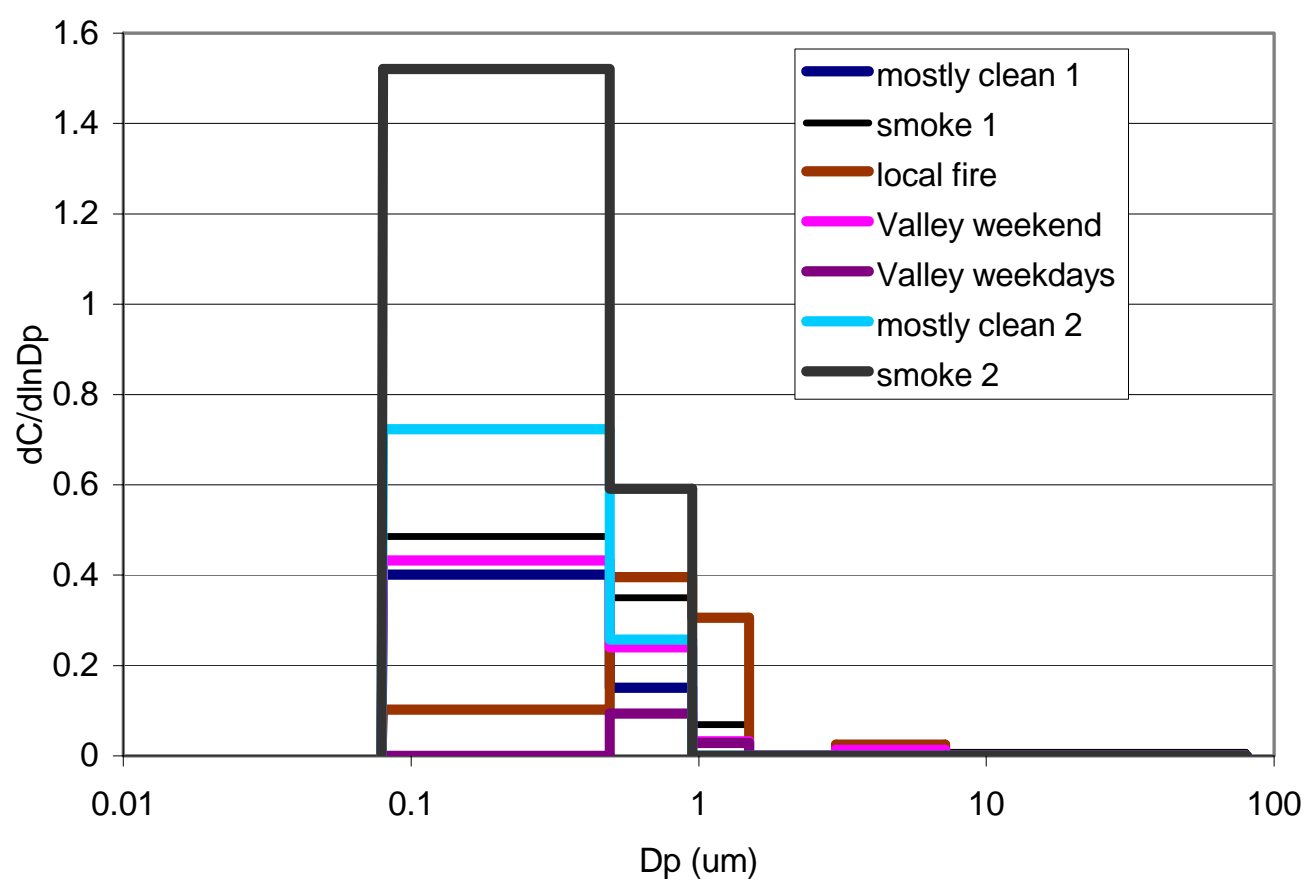

Figure I. Particle size distributions of adipic acid during YACS. 